\title{
Do Stereoisomers of Homocysteic Acid Exhibit Different Convulsant Action in Immature Rats?
}

\author{
P. MARE Š ${ }^{1}$, J. FOLBERGROVÁ ${ }^{1}$, R. HAUGVICOVÁ ${ }^{1}$, H. KUBOVÁ ${ }^{1}$ \\ ${ }^{1}$ Department of Developmental Epileptology, Institute of Physiology of the Czech Academy of \\ Sciences, Prague, Czech Republic
}

Received March 21, 2019

Accepted September 25, 2019

\begin{abstract}
Summary
Mechanism of ictogenesis of D- and L-stereroisomers of homocysteic acid was studied in 12-day-old rats by means of antagonists of N-methyl-D-aspartate (NMDA) and alpha-amino-3hydroxy-5-methyl-4-isoxazolepropionic acid (AMPA) receptors. There was no qualitative difference between the two stereoisomers in generation of emprosthotonic (flexion) as well as generalized tonic-clonic seizures. Moderate differences were observed in the first, nonconvulsive effects of the two isomers. As generation of the two types of seizures is concerned, NMDA and AMPA participate in generalized tonic-clonic seizures whereas NMDA receptors play a dominant role in generation of flexion seizures.
\end{abstract}

\section{Key words}

Homocysteic acid • Seizures • Immature rats • NMDA antagonists - AMPA antagonists

\section{Corresponding author}

P. Mareš, Department of Developmental Epileptology, Institute of Physiology of the Czech Academy of Sciences. Vídeňská 1083, 14220 Prague 4, Czech Republic. E-mail: maresp@biomed.cas.cz

\section{Introduction}

Excitatory amino acid glutamate mediates communication between nerve cells as a ligand to three types of ionotropic receptors - AMPA, NMDA and kainate (Wisden and Seeburg 1993). Different role of first two types of receptors is generally recognized - AMPA receptors serve for fast communication between neurons, NMDA receptors are deeply involved in potentiation phenomena and memory (Meldrum 2000). Both AMPA and NMDA receptors are overexpressed during postnatal development with a peak around the end of the second postnatal week (Erdö and Wolff 1990, Insel et al. 1990, Brennan et al. 1997, Arai et al. 1997). In addition to glutamate, sulphur containing amino acids might participate in excitatory transmission. Homocysteic acid (HCA), a potent excitatory and convulsant agent, is physiologically present in the brain (Olney et al. 1987, Cuenod et al. 1990). HCA was shown to be an agonist of NMDA type of glutamate receptors (Cuenod et al. 1990) present in hippocampus and released by electrical stimulation (Klancnik et al. 1992). Presence of HCA was demonstrated in glial cells (Grandes et al. 1991).

Majority of data on the action of HCA in the nervous system was generated with a racemate (D/L-HCA) but the two stereoisomers might have different mechanisms of action (effects on NMDA and AMPA receptors) as demonstrated in experiments with intracerebroventricular application of either stereoisomer (Turski 1989). Single neuron studies yielded controversive results - Herrling described differential effects of the two stereoisomers on feline caudate neurons (Herrling et al. 1989) whereas Kilic demonstrated the same action of these isomers on cerebellar granule cells (Kilic et al. 1992). We tested convulsant action of the two stereoisomers administered intraperitoneally in developing rats where blood-brain barrier is not yet mature (Saunders 1977) and systemic administration of NMDA elicits two types of seizures - age-bound flexion (emprosthotonic) seizures and classical generalized tonicclonic seizures (Mareš and Velíšek 1992). In addition, 
there is at least a quantitative difference between the two stereoisomers with D-HCA active in lower doses than L-isomer (Mareš et al. 1997). We used an action of NMDA and AMPA receptor antagonists against seizures induced by the two stereoisomers of HCA to answer the question if D- and L-HCA have different mechanisms of action.

\section{Methods}

All procedures involving animals and their care were conducted according to the ARRIVE guidelines https://www.nc3rs.org.uk/arrive-guidelines in compliance with national (Act No 246/1992 Coll.) and international laws and policies (EU Directive 2010/63/EU for animal experiments) and the National Institutes of Health guide for the care and use of Laboratory animals (NIH Publications No. 8023, revised 1978). The experimental protocol was approved by the Ethical Committee of the Institute of Physiology of the Czech Academy of Sciences. Male Wistar rat pups 12 days old were used. Their body temperature was maintained by means of a pad heated electrically on $34^{\circ} \mathrm{C}$ (i.e.to the temperature in the nest) during whole experiment. Animals were pretreated by antagonists of excitatory amino acid NMDA receptors CGP40116 (0.1, 0.5 and $5 \mathrm{mg} / \mathrm{kg}$ $30 \mathrm{~min}$ before HCA) or MK-801 (0.1, 0.5 and $2 \mathrm{mg} / \mathrm{kg}$ $30 \mathrm{~min}$ before HCA) and/or AMPA receptors NBQX (15 and $30 \mathrm{mg} / \mathrm{kg} 15 \mathrm{~min}$ before HCA) or GYKI 52466 (10 and $20 \mathrm{mg} / \mathrm{kg} 5 \mathrm{~min}$ before HCA). All compounds were dissolved in saline, NBQX should be mildly warmed and adjusted with sodium hydroxide to a slightly alkaline $\mathrm{pH}(8.0)$ to completely solubilize this compound. The doses and interval between injection of antagonists and HCA were based on our data with pentylenetetrazolinduced seizures.

Two doses of either stereoisomer of HCA (Tocris) were administered intraperitoneally -4 and $8 \mathrm{mmol}$ of L-HCA $/ \mathrm{kg}$ and 1.4 and $4 \mathrm{mmol}$ of D-HCA $/ \mathrm{kg}$. Doses are based on our older data demonstrating different susceptibility of 12-day-old rats to the two stereoisomers (Mareš et al. 1997). Either stereoisomer was dissolved in saline and $\mathrm{pH}$ was corrected to 7 , volume of injection was always $1 \mathrm{ml}$ per $100 \mathrm{~g}$ of body weight. Each group was formed by eight animals.

Animals were observed in isolation in plastic boxes for $30 \mathrm{~min}$ and incidence of two types of seizures (flexion and generalized tonic-clonic) and mortality was registered.

Incidence was statistically compared by means of Fisher test, $\mathrm{p}<0.05$ was taken as significant.

\section{Results}

In agreement with our older data both stereoisomers were able to elicit flexion as well as generalized tonic-clonic seizures, D-isomer was active at lower doses than L-isomer. As the first signs of HCA action are concerned they were different, administration of L-HCA led to twisting of the tail and hind half of the body in all cases. D-HCA elicited these movements only exceptionally, forelimb shuffling was common. Hyperlocomotion and barrel rolling were observed after both stereoisomers.

\section{Antagonists of NMDA receptors}

Either antagonist suppressed frequent tail and body twisting elicited by L-HCA less efficiently than this less frequently appearing phenomenon induced by D-HCA. There was no difference in suppression of other behavioral phenomena appearing early after the two stereoisomers.

The competitive antagonist CGP40116 more effectively suppressed both types of seizures elicited by L-HCA than seizures induced by D-HCA (Fig. 1). The same difference was demonstrated for a noncompetitive antagonist MK-801 only for generalized tonic-clonic seizures (Fig. 2). On the contrary, flexion seizures were abolished only with the highest dose of MK-801 $(2 \mathrm{mg} / \mathrm{kg})$. As expected, antagonists were more active against lower doses of either stereoisomer.

\section{Antagonists of AMPA receptors}

Tail and body twisting elicited by L-HCA were less effectively suppressed by both NBQX and GYKI 52466 than if elicited by D-HCA. The same difference was observed in barrel rolling but not in other behavioral phenomena.

The competitive antagonist NBQX did not exhibit any significant action on either stereoisomer, only a tendency to suppression of flexion seizures elicited by D-stereoisomer was found (Fig. 3). The noncompetitive antagonist GYKI 52466 suppressed seizures elicited by L-HCA but not those elicited by D-HCA (Fig. 4). 
CGP 40116

L.HCA

D. $\mathrm{HCA}$

Flexion seizures
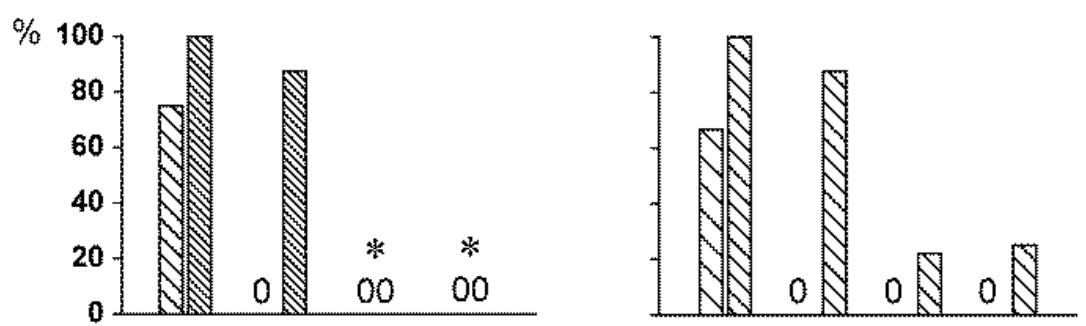

Generalized tonic-clonic seizures
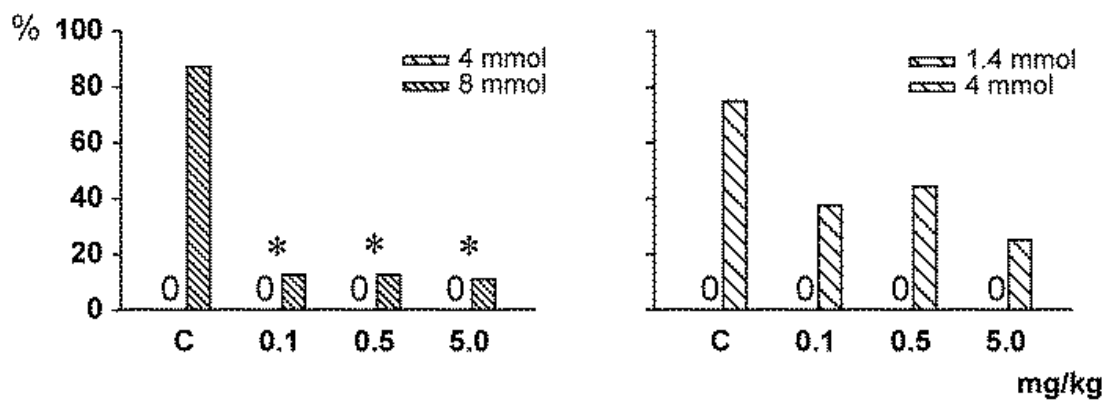

MK-801

\section{LmHCA}

Flexion seizures
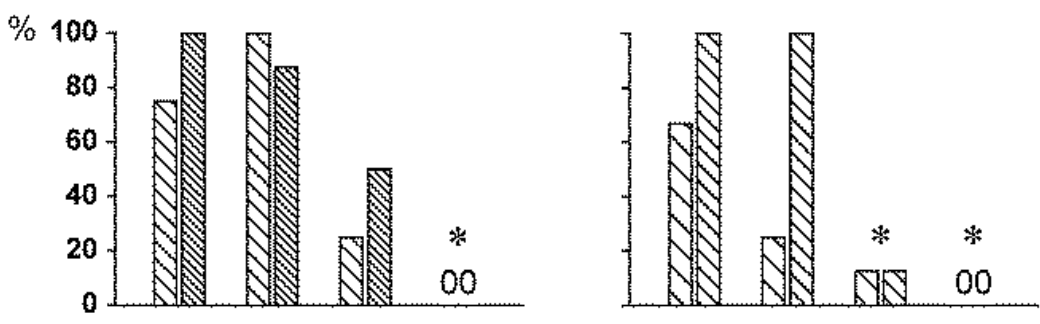

\section{Generalized tonic-clonic seizures}
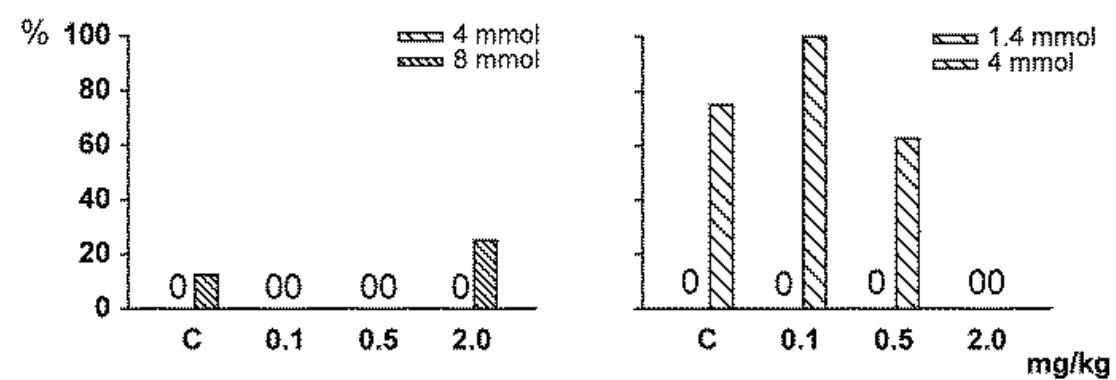

Fig. 1. Effect of CGP 40116 on incidence of seizures elicited of the two stereoisomers (L-HCA on the left, D-HCA on the right). Upper graphs - empro-sthotonic, flexion seizures, lower graphs generalized tonic-clonic seizures. X-axis: doses of the antagonist, $C$ means control rats injected with solvent; Y-axis: percentage of animals exhibiting seizures. 0 denotes absence of seizures, asterisks significant difference from controls.
Fig. 2. Effect of MK-801 on incidence of seizures elicited of the two stereoisomers. All details as in Fig. 1. 


\section{NBQX}

L-HCA D-HCA

Flexion seizures
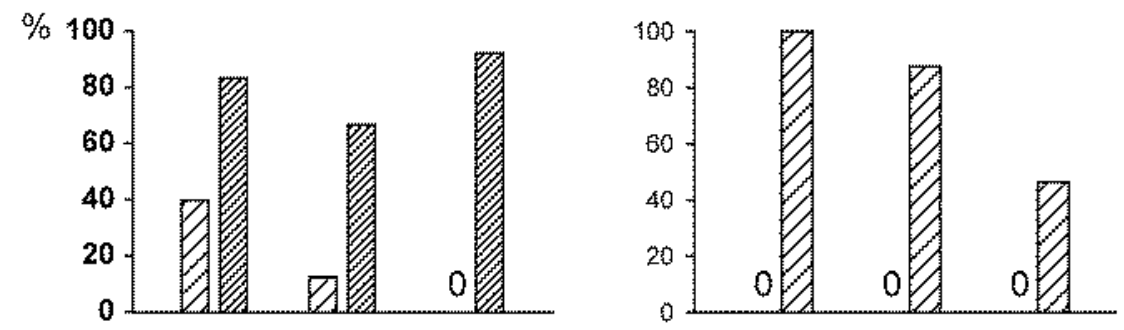

Generalized tonic-clonic seizures
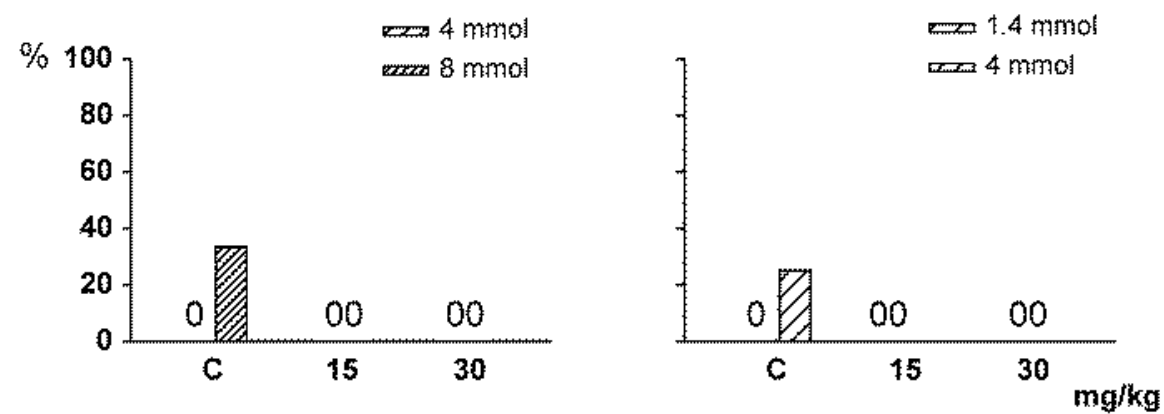

GYKI 52466

L-HCA

D-HCA

Flexion seizures
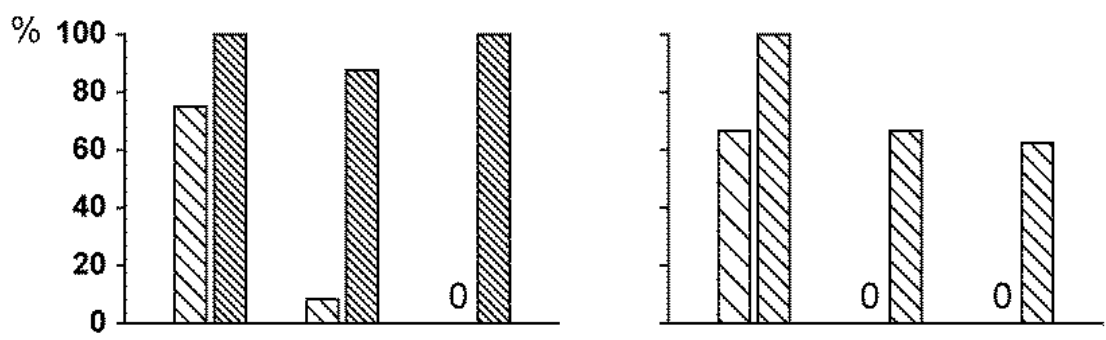

Generalized tonic-clonic seizures
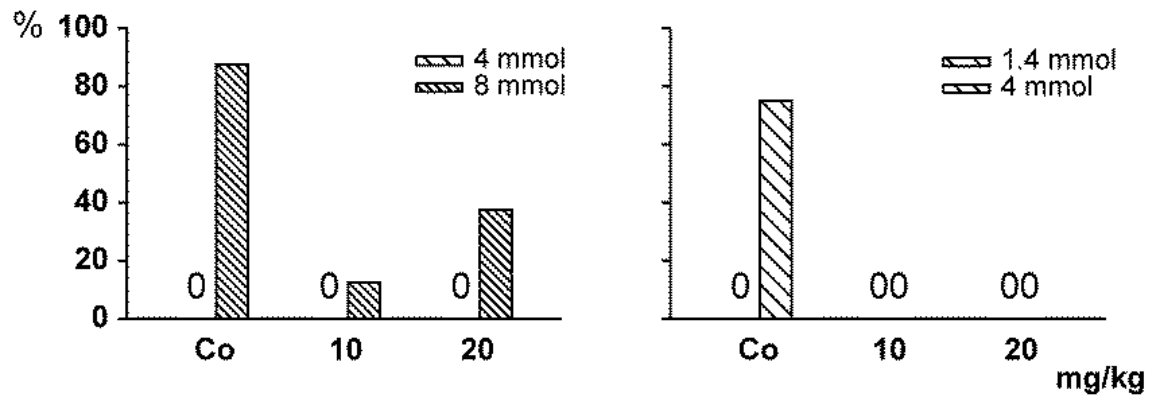

Fig. 3. Effect of NBQX on incidence of seizures elicited of the two stereoisomers. All details as in Fig. 1.
Fig. 4. Effect of GYKI 52466 on incidence of seizures elicited of the two stereoisomers. All details as in Fig. 1. 


\section{Discussion}

Our present results confirmed differences in first signs of action of the two stereoisomers as well as stronger convulsant action of D-stereoisomer in comparison with L-stereoisomer described by Turski (1989) and in our previous paper (Mareš et al. 1997). Our pharmacological results demonstrated reliable action of NMDA receptor antagonists against both types of seizures in contrast to AMPA antagonists where anticonvulsant effects were only moderate if any.

The two types of seizures (flexion and generalized tonic-clonic) are possibly generated in different brain structures by a little different mechanisms. Generalized tonic-clonic seizures are of brain stem origin with participation of more brain structures (Browning and Nelson 1985, Browning and Nelson 1986, Mareš 2006) the probable site of origin of flexion seizures is not known in spite of the fact that this type of seizures is used to model early infancy human seizures (Scantlebury et al. 2010, Velisek et al. 2007). Both ionotropic excitatory receptor systems are involved in generation of GTCS whereas NMDA is much more important than AMPA in generation of flexion seizures. GTCS are more sensitive to anticonvulsant action of NMDA antagonists than flexion seizures especially when elicited with L-stereoisomer. Generally, NMDA receptor antagonists are more active against flexion seizures than AMPA antagonists, this difference is not so marked in the case of GTCS.
We cannot explain the difference in suppression of seizures between the two AMPA antagonists NBQX (more active against flexion seizures elicited by D-isomer) and GYKI (more active against either type of seizures elicited by L-isomer). More detailed analysis should be made.

\section{Conclusions}

Seizures induced by HCA are sensitive to antagonists of both NMDA and AMPA receptors. GTCS could be more easily affected than flexion (emprosthotonic) seizures. As concerns differences between NMDA and AMPA antagonists, NMDA antagonists are more efficient against seizures elicited by L-HCA (especially flexion seizures) but this difference is only quantitative. The same mechanism of ictogenesis with a dominant role of NMDA receptors is used by both stereoisomers.

\section{Conflict of Interest}

There is no conflict of interest.

\section{Acknowledgements}

This study was funded by grant No. 18-09296S of the Grant Agency of the Czech Republic and by a project PHARMABRAIN, reg. No. CZ_02.1.01/0.0/0.0/16_025/ 0007444

\section{References}

ARAI Y, MIZUGUCHI M, TAKSHIMA S: Developmental changes of glutamate receptors in the rat cerebral cortex and hippocampus. Anat Embryol 195: 65-70, 1997.

BRENNAN EM, MARTIN LJ, JOHNSTON MV, BLUE ME: Ontogeny of non-NMDA glutamate receptors in rat barrel field cortex: II. Alpha-AMPA and kainate receptors. J Comp Neurol 386: 29-45, 1997.

BROWNING RA, NELSON DK: Variation in threshold and pattern of electroshock-induced seizures in rats depending on site of stimulation. Life Sci 37: 2205-2211, 1985.

BROWNING RA, NELSON DK: Modification of electroshock and pentylenetetrazol seizure patterns in rats after precollicular transections. Exp Neurol 93: 546-556, 1986.

CUÉNOD M, DO KQ, GRANDES P, MORINO P, STREIT P: Localization and release of homocysteic acid, an excitatory sulfur-containing amin acid. J Histochem Cytochem 38: 1713-1715, 1990.

ERDÖ SL, WOLFF JR: Postnatal development of the excitatory amino acid system in visual cortex of the rat. Changes in ligand binding to NMDA, quisqualate and kainate receptors. Int J Dev Neurosci 8: 192-204, 1990.

GRANDES P, DO KQ, MORINO P, CUÉNOD M, STREIT P: Homocysteate, an excitatory transmitter candidate localized in glia. Eur J Neurosci 3: 1370-1373, 1991.

HERRLING PL, MAEDER J, MEIER CL, DO KQ: Differential effects of (D)- and (L)-homocysteic acid on the membrane potential of cat caudate neurons in situ. Neuroscience 31: 213-217, 1989. 
INSEL TR, MILLER LP, GELHARD RE: The ontogeny of amino acid receptors in rat forebrain - I. N-methyl-Daspartate and quisqualate rceptors. Neuroscience 35: 31-43, 1990.

KILIĆ G, SCIANCALEPORE M, CHERUBINI E: Single-channel currents of NMDA type activated by L- and D-homocysteic acid in cerebellar granule cells in culture. Neurosci Lett 141: 231-235, 1992.

KLANCNIK JM, CUÉNOD M, GAHWILER BH, JIANG ZP, DO KQ: Release of endogenous amino acids, including homocysteic acid and cysteine sulphinic acid, from rat hippocampal slices evoked by electrical stimulation of Schaffer collateral-commissural fibres. Neuroscience 49: 557-570, 1992.

MARE ̌́ P: Generalized seizures in rodents - only two patterns? In: Generalized Seizures: From Clinical Phenomenology to Underlying Systems and Networks. HIRSCH E, ANDERMANN F, CHAUVEL P, ENGEL J, LOPES DA SILVA F, LUDERS H (eds), John Libbey Eurotext, Montrouge, 2006, pp 70-72.

MAREŠ P, VELÍŠEK L: N-Methyl-D aspartate (NMDA)-induced seizures in developing rats. Dev Brain Res 65 : 185-189, 1992.

MAREŠ P, FOLBERGROVÁ J, LANGMEIER M, HAUGVICOVÁ R, KUBOVÁ H: Convulsant action of D,L-homocysteic acid and its stereoisomers in immature rats. Epilepsia 38: 767-776, 1997.

MELDRUM BS: Glutamate as a neurotransmitter in the brain: review of physiology and pathology. $J$ Nutr 130 (4S Suppl): 1007S-1015S, 2000.

OLNEY JW, PRICE MT, SALLES KS, LABRUYERE J, RYERSON R, MAHAN K, FRIERDICH G, SAMSON L: L-Homocysteic acid: an endogenous excitotoxic ligand of the NMDA receptor. Brain Res Bull 19: 597-602, 1987.

SAUNDERS NR: Ontogeny of the blood-brain barrier. Exp Eye Res 25 (Suppl): 523-550, 1977.

SCANTLEBURY MH, GALANOPOULOU AS, CHUDOMELOVA L, RAFFO E, BETANCOURTH D, MOSHÉ SL: A model of symptomatic infantile spasms syndrome. Neurobiol Dis 37: 604-612, 2010.

TURSKI WA: Homocysteic acid: convulsant action of stereoisomers in mice. Brain Res 479: 371-373, 1989.

VELÍSEK L, JEHLE K, ASCHE S, VELÍSKOVÁ J: Model of infantile spasms induced by N-methyl-D-aspartic acid in prenatally impaired brain. Ann Neurol 61: 109-119, 2007.

WISDEN W, SEEBURG PH: Mammalian ionotropic glutamate receptors. Prog Neurobiol 42: 291-298, 1993. 